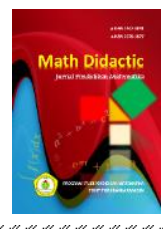

MATH DIDACTIC: JURNAL PENDIDIKAN MATEMATIKA

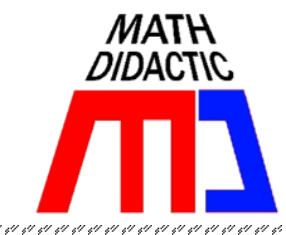

\title{
PENGGUNAAN BLOG-GOTHIC PADA MATA KULIAH GEOMETRI ANALITIK
}

\author{
BLOG-GOTHIC USE IN ANALYTICAL GEOMETRY SUBJECT
}

Rohmah Indahwati, Chairul Fajar Tafrilyanto

Prodi Pendidikan Matematika Universitas Madura, Prodi Pendidikan Matematika Universitas Madura indah_math@unira.ac.id, chairul_math@unira.ac.id.

\begin{abstract}
Abstrak: Satu dari empat kompetensi yang harus dimiliki guru dan dosen adalah kompetensi profesional. Seorang dosen harus mampu menguasai dan mengembangkan materi sesuai dengan bidang ilmu yang diampu serta dapat memanfaatkan kemajuan teknologi, informasi, dan komunikasi (TIK) sebagai media komunikasi yang menunjang kegiatan belajar mengajar. Sama halnya dengan mahasiswa yang mempunyai kemampuan bertanya dan berargumentasi yang berbeda. Mahasiswa hanya sedikit merespon atau memberikan solusi dari masalah yang diberikan yang disebabkan kurangnya media untuk mengekspresikan diri dalam bertanya secara bebas tanpa merasa malu serta keterbatasan jam tatap muka. Media blog sebagai salah satu media pembelajaran melalui internet atau media interaksi antara mahasiswa dan dosen. Penggunaan media ini sebagai salah alternatif dalam mengatasi keterbatasan jam tatap muka selama perkuliahan dan tentunya memanfaatkan kemajuan teknologi informasi dan komunikasi yang berkembang saat ini. Blog yang dimaksud diberi nama blog-gothic sebagai pusat pembelajaran yang di dalamnya berisi rencana perkuliahan, bahan ajar, tugas link referensi, video serta bahan diskusi pada mata kuliah geometri analitik. Selain itu tersedia blog dosen dan mahasiswa untuk saling berinteraksi. Terdapat juga suatu komunitas blogger pembelajar yang memungkinkan adanya interaksi dan komunikasi antar dosen dan mahasiswa serta dari berbagai universitas bisa tergabung dalam komunitas blogger pembelajar tersebut.
\end{abstract}

Kata Kunci: Blog-Gothic, Geometri Analitik

Abstract: One of the four competencies that teachers and lecturers must possess is professional competence. A lecturer must be able to master and develop material in accordance with the field of science that is taught and can take advantage of advances in technology, information, and communication (ICT) as a communication medium that supports teaching and learning activities. Similarly for students who have the ability to ask questions and argue differently. Students only give a little bit solution to the problem given due to the lack of media to express themselves in asking freely without feeling embarrassed and the limitations of face-to-face hours. Blog media as one of the learning media through the internet or media interaction between students and lecturers. The use of this media as an alternative in overcoming the limitations of face-to-face hours during lectures and of course utilizing the progress of information and communication technology that is developing at this time. The blog in question is given the name of a gothic blog as a learning center which includes lecture plans, teaching materials, assignments of reference links, videos and discussion material on the subject of analytical geometry. In addition, there are lecturer and student blogs to interact with each other. There is also a community of learning bloggers that allows interaction and communication between lecturers and students as well as from various universities to join the blogger learning community.

Keywords: Blog-Gothic, Analytical Geometry

Cara Sitasi: Indahwati, R., \& Tafrilyato, C.F. (2018). Penggunaan blog-gothic pada mata kuliah geometri analitik. Math Didactic: Jurnal Pendidikan Matematika, 4 Edisi Dies Natalis XXXII, 310-318. 
Sesuai dengan Undang - undang No.14 Tahun 2015 tentang guru dan dosen dijelaskan bahwa dosen harus mempunyai kompetensi - kompetensi yang meliputi: 1) kompetensi pedagogis 2) kompetensi profesional 3) kompetensi sosial dan 4) kompetensi kepribadian. Kompetensi profesional ini berhubungan dengan bagaimana mereka mampu menguasai dan mengembangkan materi sesuai dengan bidang ilmu yang diampu serta dapat memanfaatkan kemajuan Teknologi, Informasi, dan Komunikasi (TIK) sebagai media komunikasi yang menunjang kegiatan belajar mengajar. Oleh sebab itu, dosen harus mampu menjawab dua tantangan utama saat ini, yaitu perubahan persepsi tentang belajar itu sendiri dan tantangan dari kemajuan teknologi informasi dan telekomunikasi yang berkembang begitu pesat (Kristiyanti, 2011).

Pada umumnya, mahasiswa mempunyai kemampuan bertanya dan berargumentasi yang berbeda serta yang mampu merespon ataupun memberikan sedikit solusi dari suatu permasalahan. Hal ini dikarenakan kurangnya media untuk mengekspresikan diri dalam bertanya secara bebas tanpa merasa malu serta keterbatasan jam tatap muka. Sehingga dibutuhkan suatu media yang memungkinkan siswa dapat berpartisipasi aktif secara bebas yang dapat diakses di luar jam perkuliahan. Proses persiapan dan perencanaan pembelajaran memerlukan media yang dapat membantu siswa dan juga guru yang berperan sebagai " Guide on the side" menggantikan "sage on the stage" (Slavin, 2008) untuk mengoptimalkan kegiatan belajar mengajar.
Kata "Media" berasal dari bahasa latin yang merupakan bentuk jamak dari "medium", secara harfiah berarti perantara atau pengantar (Nurseto, 2011, hal. 20). Romiszowski dalam Angkowo \& Kosasih (2007:14) media dikatakan sebagai " as the carriers on messages, from some transmittingsource (which may be a human being or inanimate object), to receiver of the message (which in our case is the learner). Sedangkan menurut Arsyad (2010, hal. 248) media pembelajaran adalah perantara yang berupa sumber belajar atau wahana fisik yang mengandung materi instruksional yang Dapat dimanfaatkan siswa untuk menunjang kegiatan belajar. Lebih lanjut Arsyad menjelaskan bahwa media pembelajaran dapat memperjelas penyajian pesan dan informasi sehingga dapat memperlancar dan meningkatkan proses dan hasil belajar.

Salah satu media yang mudah dibuat dan cukup efektif adalah Blog yang merupakan sebuah media alternatif pembelajaran melalui internet atau media interaksi antara mahasiswa dengan dosen. Media ini dapat dijadikan alternatif untuk mengatasi masalah keterbatasan jam tatap muka selama perkuliahan dengan memanfaatkan kemajuan teknologi komunikasi dan informasi yang berkembang saat ini.

$$
\text { Scot dalam (Zake, 2010) }
$$
mengungkapkan bahwa sebuah blog adalah situs yang dibuat dan berisi entri-entri yang ditulis dan ditampilkan dalam urutan kronologis terbalik. Blog diperkenalkan pada pertengahan tahun 1990an (Farmer, Yue, \& Brooks dalam Zake, 2010) dan mudah digunakan karena pengguna tidak perlu pengetahuan teknis canggih sehingga bisa dibuat oleh semua kalangan.

Penggunaan Blog sebagai sebagai media pembelajaran sekaligus sebagai sumber belajar sedikitnya akan mengubah 
cara belajar dan teknik pembelajaran agar tidak monoton sehingga dapat memotivasi mahasiswa dalam mempelajari sesuatu serta gratis. Blog juga sekaligus berfungsi sebagai media interaksi dan berdiskusi antara dosen dengan mahasiswa, mahasiswa dengan mahasiswa, dosen dengan dosen lain, pembelajar suatu tempat dengan pembelajar tempat lainnya dan seterusnya. Hal ini sesuai dengan pendapat Huette (2006, hal. 5) memaparkan keuntungan dari penggunaan blog di ruang kelas antara lain : 1) dapat mempromosikan berpikir kritis dan analitis, 2) dapat mendorong kreatif, berpikir intuitif dan asosiasional, 3) dapat mendorong berpikir analogis, 4) potensi peningkatan akses dan paparan untuk informasi berkualitas, dan 5) kombinasi interaksi solidaritas dan sosial.

Berdasarkan data tersebut ketersediaan jaringan internet di kalangan mahasiswa masih belum dapat dimanfaatkan seorang dosen untuk merancang media pembelajaran berupa blog. Blog yang dimaksud adalah Blog Gothic (Blog Geometry Analitic)

\section{Blog}

\section{a. Pengertian Blog}

Di zaman yang serba modern ini, hampir setiap pengguna internet di Indonesia membicarakan mengenai Blog. Blog merupakan singkatan dari" Web log" sebenarnya mulai dikenal sejak tahun 1997, namun baru populer pada tahun 2000. Blog adalah bentuk aplikasi web yang menyerupai tulisan-tulisan (yang dimuat sebagai posting) pada sebuah halaman web umum. Tulisantulisan ini sering kali dimuat dalam urut terbalik (isi terbaru dahulu baru kemudian diikuti isi yang lebih lama), meskipun tidak selamanya demikian. Saat ini, Blog sudah menjadi bagian tak terpisahkan dari dunia WWW dan dunia per-internet-an. Blog sudah mulai dijadikan sebagai sumber berita oleh koran-koran, majalah, radio, bahkan televisi juga sudah menyiarkan beritanya lewat Blog mereka. Dunia pendidikan pun sudah banyak menampilkan materi pendidikan di dalam Blog yang telah dibuat khusus maupun tidak khusus untuk dunia pendidikan (Kristiyanti, 2011).

Salah satu platform blog yang cukup populer sampai saat ini diperkenalkan oleh Pyra Lab dengan nama situsnya Blogger.com, namun kepemilikannya telah diakuisisi pada tahun 2002 oleh Google dan lebih dikenal dengan nama lain yaitu Blogspot. Sebenarnya ada banyak platform yang bisa digunakan sebagai media untuk membuat blog, dua platform yang cukup terkenal dan mudah dalam pengoperasiannya hingga saat ini adalah Blogger.com (Blogspot) dan Wordpress.com.

b. Fungsi Blog sebagai Media Pembelajaran

Media pembelajaran adalah sebuah alat yang berfungsi untuk menyampaikan pesan pembelajaran. Berdasarkan pengertian tersebut maka Blog tentunya dapat dijadikan sebagai salah media dalam pembelajaran. Adapun pola penggunaan Blog sebagai media pembelajaran sebagai berikut:

1) Dosen membuat Blog dan masingmasing mahasiswa harus sudah mempunyai Blog juga. 
2) Blog pengajar dalam hal ini sebagai pusat pembelajaran sekaligus sebagai Blog Aggregator atau Blog dengan beberapa kontributor dengan dosendosen dan mahasiswa dari berbagai universitas bisa tergabung dalam komunitas blogger pembelajar tersebut.

3) Pengajar dapat menyediakan materi pembelajaran/tugas melalui fasilitasfasilitas yang sudah disediakan oleh Blog seperti memosting langsung maupun dengan tautan (link)

4) Untuk memberikan tugas Gang berbeda pada setiap mahasiswa, dosen dapat memostingnya langsung dengan menyisipkan file yang dapat diunduh siswa.

5) Mahasiswa mempelajari materi yang telah diberikan dosen dan dapat memberikan komentar atau pertanyaan melalui fasilitas komentar.

6) Dosen dapat membuka forum diskusi melalui fasilitas-fasilitas yang telah disediakan pada Blog

7) Banyak aplikasi yang dapat diintegrasikan dengan Blog dan dapat digunakan untuk media pembelajaran seperti Study Groups, Course Feed dan lain sebagainya

8) Mahasiswa dituntut aktif untuk mencari bahan yang terkait dengan materi pembelajaran dan melakukan sharing dengan temannya.

9) Menindaklanjuti semua kegiatan tersebut dalam pertemuan tatap muka.

10) Evaluasi dilaksanakan dengan tatap muka secara offline

\section{c. Fitur-fitur Blog sebagai Media Pembelajaran}

Banyak fitur yang ditawarkan Blog sebagai layanan yang dapat digunakan oleh user dalam rangka memudahkan interaksi. Jika ditelaah lebih dalam, beberapa diantaranya dapat dimanfaatkan sebagai media pembelajaran. fitur-fitur Blog adalah :

1) Post yaitu sebuah tulisan yang terpisah dengan tulisan-tulisan lainnya yang ada di dalam blog (menggambarkan isi dari Blog)

2) Komentar yaitu fasilitas yang memberi kesempatan bagi para pengunjung sebuah blog untuk memberikan tanggapan mengenai tulisan dalam Blog.

3) Tautan (link) yaitu sebuah tulisan yang menghubungkan antara sebuah halaman website dengan halaman yang lain.,

4) Blogroll yaitu kumpulan tautan atau link dari halaman blog atau halaman web yang sering dikunjungi oleh pemilik blog,

5) Sidebar yaitu bagian dari sebuah halaman blog yang berada di samping kiri, kanan atau keduanya.

6) Sindikasi yaitu sebuah tulisan yang bisa dibaca di tempat lain tanpa mengunjungi blog itu sendiri, dan blog aggregator. Blog juga terdiri dari berbagai jenis, yaitu blog sebagai buku harian, linkfest, clubhouses, soapboxes, dan newsroom.

\section{d. Cara membuat blog}

Cara membuat blog tidak terlalu sulit, karena tidak perlu ahli dalam bidang komputer serta menguasai pemrograman dan sintaks yang rumit. Sebelum membuat blog, harus membuat email terlebih dahulu. Alamat email 
yang digunakan adalah gmail. Dengan langkah-langkah dalam membuat Blog di blogger sebagai berikut :

1) Masuk ke situs di blogger di http://blogger.com

2) Lihat bagian kanan bawah, ubahlah bahasa menjadi bahasa Indonesia agar lebih mudah dipahami

3) Login/masuk menggunakan nama/username pengguna serta password gmail (akun email bisa juga untuk login ke blogger)

4) Kemudian isi formulir data yang terlampir yaitu :

- Nama tampilan : bisa diisi dengan nama yang akan ditampilkan pada profil blog

- Jenis kelamin : pilih jenis kelamin yang sesuai, misalnya : Pria atau wanita

- Penerimaan Persyaratan : Ceklis sebagai tanda setuju dengan peraturan yang telah ditetapkan oleh pihak blogger.

5) Klik tanda panah dengan tulisan "Lanjutkan". Kemudian klik "Blog Baru"

6) Selanjutnya isi formulir data blog pada form yang disediakan seperti :

- Judul : Isilah dengan judul sesuai keinginan

- Alamat : Isilah dengan alamat blog yang dinginkan

- Template : pilih template (tampilan blog) yang disukai

7) Kemudian klik tombol "Buat blog"

8) Sampai dengan tahap ini blog sudah selesai dibuat, namun untuk menghindari anggapan spam oleh google sebaiknya dibuat suatu artikel, minimal 1 postingan
9) Kemudian klik tulisan "Mulai memposkan"

10) Isi judul dan artikel yang dipostkan di blog

11) Setelah tulisan selesai lalu klik "pratinjau" untuk melihat hasil sementara, jika telah selesai maka klik "publikasikan"

\section{Geometri Analitik}

Geometri analitik adalah suatu cabang ilmu matematika yang merupakan kombinasi antara aljabar dan geometri. Dengan membuat korespondensi antara persamaan matematika secara aljabar dengan tempat kedudukan secara geometrik diperoleh suatu metode pemecahan masalah geometri yang lebih sistematik dan lebih tegas. Masalah-masalah geometri akan diselesaikan secara aljabar (atau secara analitik). Sebaliknya gambar geometri sering memberikan pemahaman yang lebih jelas pada pengertian hasil secara aljabar. Dalam hal ini juga memungkinkan menyelesaikan masalah aljabar secara geometri, tetapi model bentuk geometri jauh lebih penting daripada sekedar penyelesaian, khususnya jika bilangan dikaitkan dengan konsep pokok geometri. Sebagai contoh, panjang suatu segmen garis atau sudut antara dua garis. Jika garis dan titik secara geometrik diketahui, maka bilangan yang menyatakan panjang atau besar sudut antara dua garis pada hakikatnya hanyalah nilai pendekatan dari suatu pengukuran. Tetapi metode aljabar memandang bilangan itu sebagai perhitungan yang eksak (www.directory.umm.ac.id).

Menurut Imswatama (2015), adapun kesulitan - kesulitan dalam mata kuliah 
geometri analitik secara umum meliputi 3 hal berikut:

1. Kesulitan memahami konsep yaitu kesulitan yang terjadi ketika mahasiswa membuat kesalahan dalam menjawab pertanyaan yang berkaitan dengan konsep-konsep geometri

2. Kesulitan memahami prinsip yaitu kesulitan yang terjadi ketika mahasiswa melakukan kesalahan dalam penggunaan rumus dan teorema, atau mahasiswa mengetahui mengenai rumus tersebut namun salah dalam proses pengerjaannya.

3. Kesulitan melakukan operasi aljabar yaitu kesulitan yang terjadi ketika mahasiswa melakukan kesalahan dalam proses perhitungan aljabar.

\section{Blog-Gothic pada Mata Kuliah Geometri} Analitik

$$
\text { Blog - Gothic (Blog Geometry }
$$

Analitic) sebagai pusat pembelajaran yang dirancang di dalamnya akan berisi rencana perkuliahan, bahan ajar, tugas, link referensi, video serta bahan diskusi. Fiturfitur blog saling terkait dan mendukung dalam media ini, yaitu Post yang akan menggambarkan isi dari Blog, Komentar yaitu fasilitas yang memberi kesempatan tanya jawab antar mahasiswa ataupun mahasiswa dan dosen untuk meningkatkan pemahaman terhadap materi yang sedang dibahas, Tautan (link) untuk saling berbagi alamat website tentang referensi bahan perkuliahan, Blogroll yang merupakan kumpulan link ataupun Blog yang sering dikunjungi, Sidebar, serta Sindikasi.

Selain itu blog dosen dan mahasiswa juga dapat saling berinteraksi. Mahasiswa diharuskan memiliki blog masing-masing, sebagai sarana mengerjakan tugas-tugas yang diberikan oleh dosen. Metode ini bisa memacu iklim kompetisi antar mahasiswa, karena tentu saja mereka ingin blognya menjadi yang terbaik. Setelah semua mahasiswa memiliki Blog dibuatlah suatu komunitas blogger pembelajar. Ada sebuah Blog, yaitu Blog Gothic itu sendiri sebagai pusat pembelajaran tadi yang berupa Blog Aggregator atau blog dengan beberapa kontributor dengan dosendosen dan mahasiswa dari berbagai universitas bisa tergabung dalam komunitas Blogger pembelajar

\section{Penggunaan Blog-Gothic pada mata} kuliah geometri analitik adalah sebagai berikut :

a. Post yaitu tulisan yang terpisah dengan tulisan-tulisan lainnya yang ada di dalam blog (menggambarkan isi dari blog). Dalam hal ini berkaitan dengan artikel tentang materi-materi pada mata kuliah geometri Analitik.

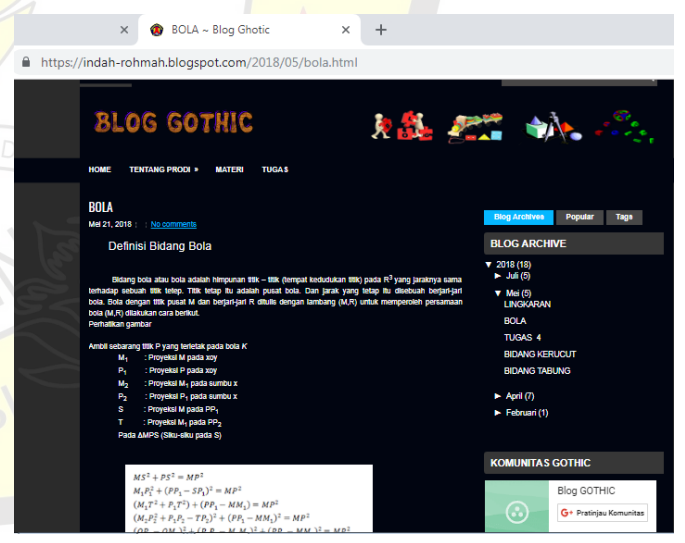

Gambar 1. Contoh post tentang bidang bola

b. Komentar yaitu kolom yang memberi kesempatan bagi para pengunjung pengunjung Blog-Gothic untuk memberikan tanggapan mengenai tulisan yang ada di dalam blog. 


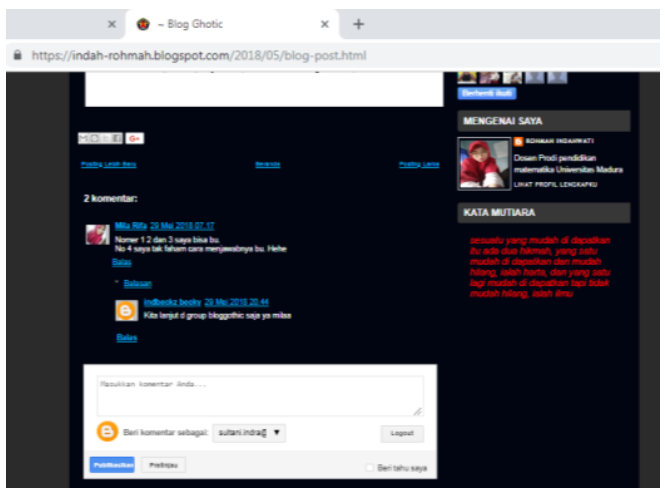

Gambar 2. Kolom komentar

c. Video yaitu sisipan berupa video untuk membantu menjelaskan sesuatu materi.

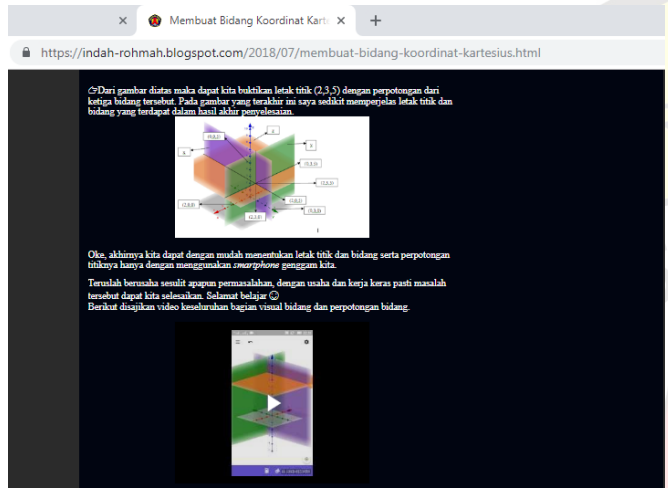

Gambar 3. Tempat untuk menyimpan video

d. Sidebar yaitu bagian dari sebuah halaman blog yang berada di samping kiri, kanan atau keduanya.

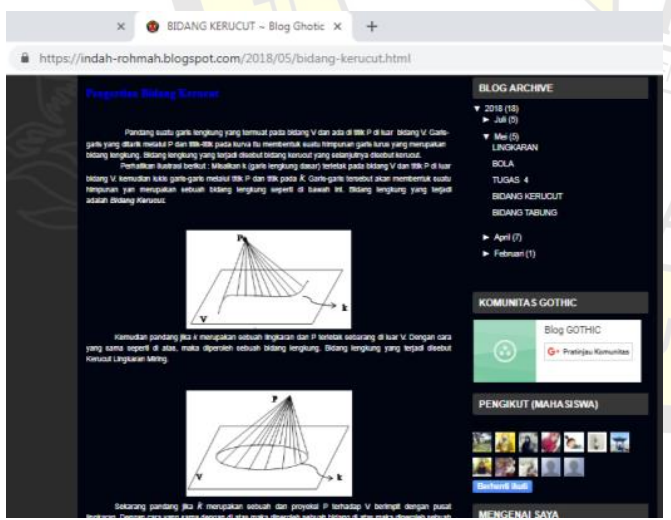

Gambar 4. Tampilan Sidebar

e. Group, dalam Blog-Gothic ini berupa group "Komunitas Gothic" yang di dalamnya beranggotakan mahasiswa mata kuliah geometri analitik dan beberapa dosen dari perguruan tinggi lain

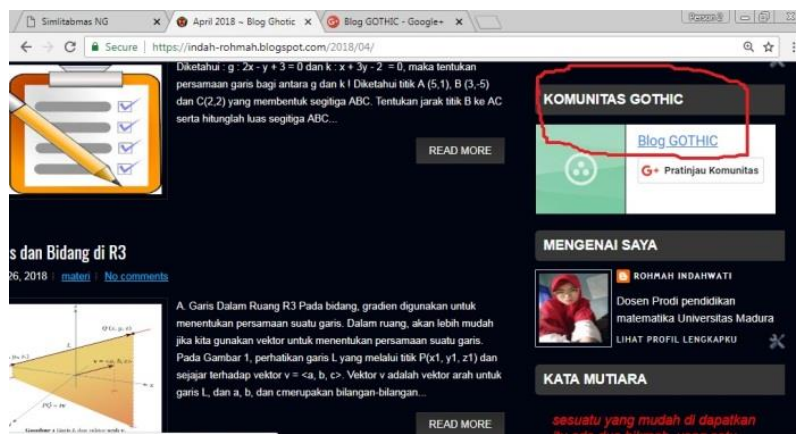

Gambar 5. Group Komunitas Ghotic

f. Jika Komunitas Gothic diklik maka anggota komunitas akan terhubung ke halaman group seperti di bawah ini :

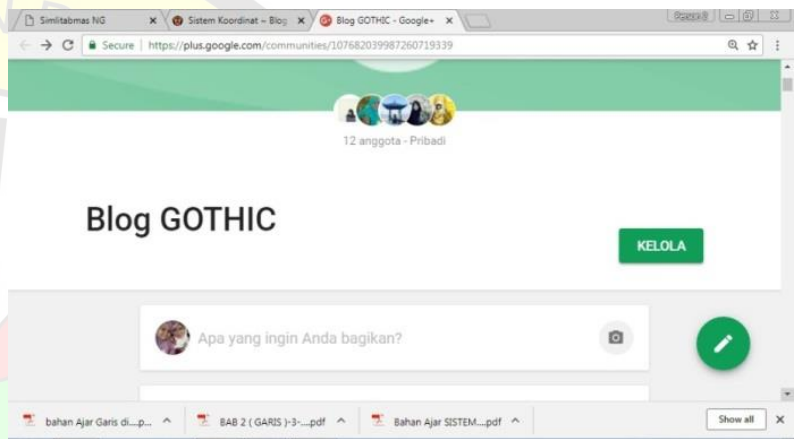

Gambar 6. Koneksi untuk anggota komunitas gothic

g. Pada halaman komunitas Gothic, setiap anggota komunitas mempunyai fasilitas untuk saling berbagi informasi maupun berdiskusi tentang segala hal yang menyangkut perkuliahan geometri analitik. Beberapa mahasiswa langsung memanfaatkan group untuk menyampaikan kesulitannya pada suatu soal. Melihat respon yang begitu cepat dari beberapa mahasiswa, mengindikasikan bahwa adanya antusias dalam berbagi informasi ataupun saling bertanya dan merespon satu sama lain, antar mahasiswa dan dosen . Berikut gambar aktivitas diskusi mahasiswa dan dosen 


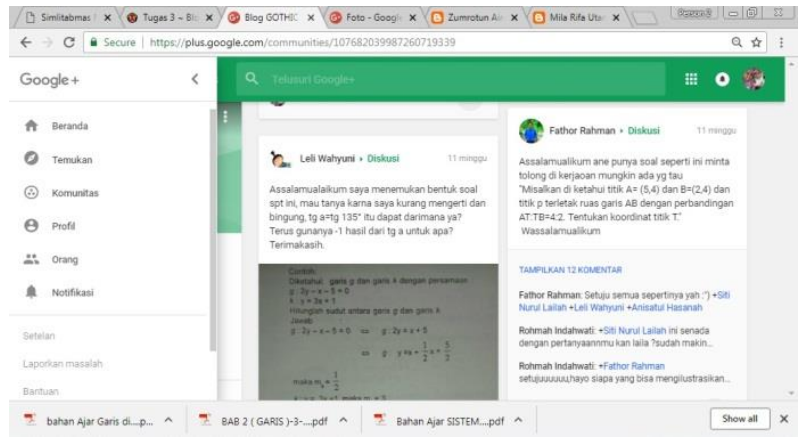

Gambar 7. Aktivitas mahasiswa dalam menggunakan blog-gothic

h. Gambar di atas merupakan screenshoot yang memperlihatkan bagaimana komunikasi yang dilakukan oleh mahasiswa. Selain itu, peneliti juga merespon diskusi-diskusi yang dilakukan oleh mahasiswa,seperti yang terlihat pada gambar di bawah ini:

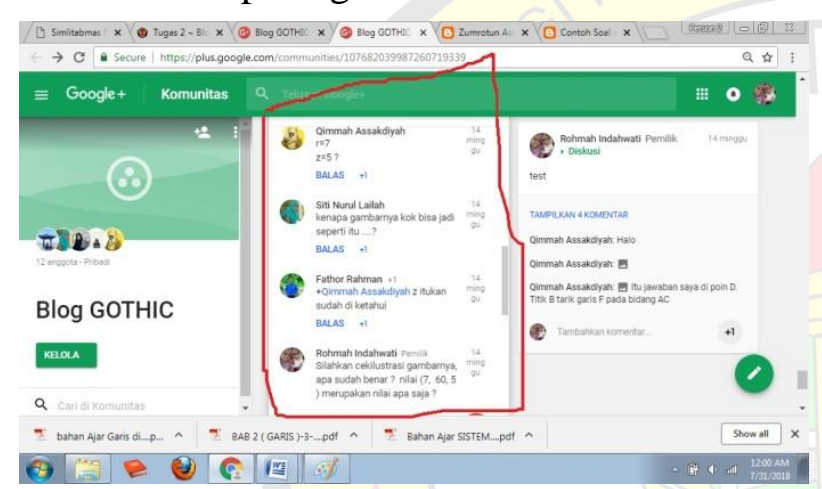

Gambar 8. Tampilan percakapan mahasiswa di grup Ghotic

i. Berdasarkan percakapan pada hasil screenshot di atas terlihat bahwa mahasiswa mulai berani merespon tanpa takut salah terhadap pertanyaan yang diajukan oleh temannya.

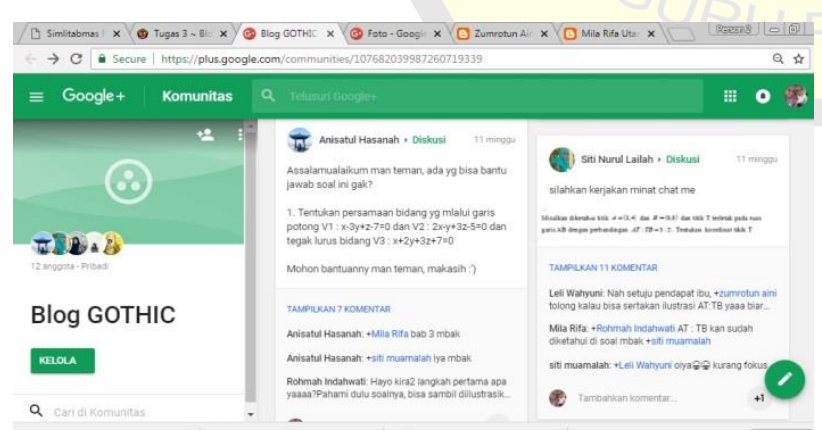

Gambar 9. Respon mahasiswa menggunakan bloggothic

Selain yang tertulis di atas sebagai pusat pembelajaran dalam berinteraksi dengan mahasiswa. Dosen juga bisa mengisi dengan perangkat pembelajaran yang berisi rencana perkuliahan, bahan ajar, tugas, link referensi, video serta bahan diskusi pada mata kuliah geometri analitik. Terdapat juga suatu komunitas blogger pembelajar yang memungkinkan adanya interaksi dan komunikasi antar dosen dan mahasiswa serta dari berbagai universitas bisa tergabung dalam komunitas blogger pembelajar tersebut.

\section{Ucapan Terima Kasih}

Ucapan terima kasih disampaikan kepada: (1) DRPM KEMENRISTEKDIKTI atas pendanaan penelitian dosen pemula (PDP) berdasarkan Surat Keputusan Nomor 120/SP2H/LT/DRPM/2018 dan Perjanjian/Kontrak Nomor 075/H.03/LPPMUNIRA/IV/2018, (2) Universitas Madura atas segala kesempatan, dukungan dan motivasi sehingga peneliti bisa menyelesaikan laporan ini sesuai waktu yang ditentukan.

\section{Daftar Pustaka}

Angkowo R dan A Kosasih. 2007. ptimalisasi Media Pembelajaran. Jakarta: PT. Grasindo.

Arsyad, A. 2010. Media Pembelajaran. Jakarta : Raja Grafindo Persada.

Huette, S. 2006. Blogs in Education. University of Oregon. Tersedia pada http://tep.uoregon.edu/shared/blogswiki spodcasts/Blogs In Education

Imswatama, Aritsya dan Nur'aini Muhassanah. 2015. Analisis Kesulitan Mahasiswa Dalam Menyelesaikan Soal Geometri Analitik Bidang Materi Garis dan Lingkaran. Seminar Nasional Matematika dan 
Pendidikan Matematika Universitas Negeri Yogyakarta. Halaman : 41-48

Kristiyanti, Mariana. 2011. Blog Sebagai Alternatif Media Pembelajaran.

Majalah Ilmiah Informatika Vol. 2 No.

2 , halaman : 33- 45

Nurseto, Tejo. 2011. Membuat Media Pembelajaran yang Menarik. Jurnal Ekonomi \& Pendidikan, 8 (1) : 19-35

Slavin, R. E. 2008. Psikologi pendidikan teori dan praktik, Edisi kedelapan. Jakarta: Indeks.

Zake, J. W. F. M., Parkes, M., \& S, Gregory. 2010. Blogging at university as a case study in instructional design: Challenges and suggestions towards professional development. International Journal of Education and Development using Information and Communication Technology. 6 (1). 